\title{
Urban land use effect analysis on the level of noise pollution using satellite and GIS technologies: A case study in Tehran city
}

\author{
Naji F.K. ${ }^{1}$, Djahed B. ${ }^{2}$, Mahvi A.H. ${ }^{1,3^{*}}$, Nowrouz P. ${ }^{4}$, Nazmara S. ${ }^{1,3}$ and Kardooni H. ${ }^{5}$ \\ ${ }^{1}$ Department of Environmental Health Engineering, School of Public Health, Tehran University of Medical Sciences, Tehran, Iran \\ ${ }^{2}$ Department of Environmental Health Engineering, School of Public Health, Iranshahr University of Medical Sciences, Iranshahr, Iran \\ ${ }^{3}$ Center for Solid Waste Research, Institute for Environmental Research, Tehran University of Medical Sciences, Iran \\ ${ }^{4}$ Department of Environmental Health Engineering, School of Public Health and Safety, Shahid Beheshti University of Medical Sciences, \\ Tehran, Iran \\ ${ }^{5}$ Environmental and Occupational Health Center, Ministry of Health and Medical Education, Tehran, Iran \\ Received: 27/04/2020, Accepted: 09/08/2020, Available online: 23/09/2020 \\ *to whom all correspondence should be addressed: e-mail: ahmahvi@yahoo.com \\ https://doi.org/10.30955/gnj.003337
}

\section{Graphical abstract}

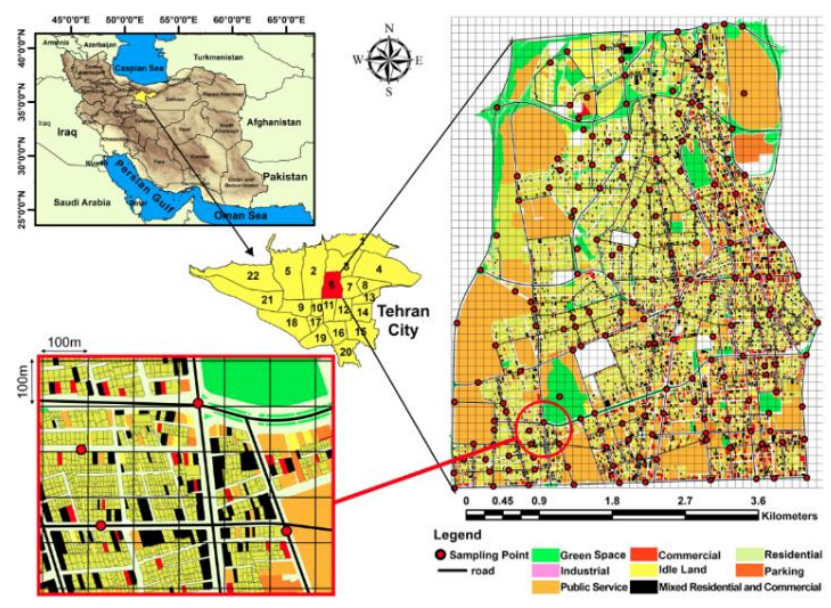

\section{Abstract}

We utilized satellite and GIS technologies to address the relationship between urban land uses and Noise Pollution (NP) in one of the most crowded regions of Tehran city. Leq was determined in 170 stations of the studied area and an acoustic map was created. Moreover, using satellite remote sensing data and a land use map, the density map for nine types of the most important urban land use was provided and the relationship between different land use densities and NP was investigated. We found that the investigated region was highly polluted and the NP level was higher in the morning $(76.29 \pm 5.61 \mathrm{~dB}[\mathrm{~A}])$ and afternoon $(76.46 \pm 4.88 \mathrm{~dB}[\mathrm{~A}])$ in comparison to the noon period. Furthermore, the prepared acoustic map revealed that in the east and southwest of the studied area, the NP was highest and lowest, respectively. Also, cultural (73.48 $\pm 4.7 \mathrm{~dB}[\mathrm{~A}])$ and parking $(79.02 \pm 4.3 \mathrm{~dB}[\mathrm{~A}])$ areas had the lowest and highest levels of Leq. Also, the high density of road, commercial, industrial, mixed commercial and residential and parking land uses had a direct significant relationship with Leq and this relation was inverse for green space. It was concluded that land use variations significantly affect the NP levels and it can be utilized to predict and manage the NP in different cities.

Keywords: noise pollution, acoustic mapping, land use, Tehran, Iran

\section{Introduction}

Nowadays, around $54 \%$ of the population lives in cities, and by 2050 , the population is expected to reach $66 \%$ (Margaritis and Kang, 2017). This ever-increasing rate of population leads to a significant increase in environmental problems. Among the different environmental problems, noise is one of the most important pollutions (Hamed and Effat, 2007) and it is considered a growing problem (Aparicio-Ramon et al., 1993; Hunashal and Patil, 2012; Lercher, 1996; Williams and McCrae, 1995) that considerably affects the life quality in the big cities (Abbaspour et al., 2015). Noise pollution (NP) is an unwanted sound (Barrigón Morillas et al., 2002; Kisku et al., 2006). The monitoring and management of NP are different from other urban pollutants due to its source features as well as its release form. People pay less attention to NP compared to other problems such as air pollution and water pollution due to its invisibility, short decay time and difficulty to associate cause with effect (Alam, 2011; Jamrah et al., 2006). NP has harmful effects on humans (Abbaspour et al., 2015; Hunashal and Patil, 2012; Lagonigro et al., 2018). According to the reports of the world health organization (WHO), after air pollution, noise is the biggest cause of health problems around the world (Barrigón Morillas et al., 2002). It can affect the human health by its physical (hearing defects), physiological (increased blood pressure), psychological (insomnia, irritability, and stress), and functional (reduction of productivity and misunderstanding what is heard) aspects (Abbaspour et al., 2015; Alesheikh and Omidvari, 2010; Hunashal and Patil, 2012; Langdon, 1976; Ouis, 2001), but the most important adverse effect of exposure to high 
levels of noise is deafness, which initially is temporary but can be a permanent illness over a long period (Alam, 2011). Monitoring the different noise sources in an urban area, preparing an acoustic map, and determining the areas with high NP are of central importance because it is possible to use management and engineering measures to control the noise level and its risks (Ryu et al., 2017; Xie et al., 2011).

In creating acoustic maps, in addition to the noise level, effective factors such as Urban Land Use (ULU) distribution should be considered (Steele, 2001). In an urban area, the type of ULU plays an important role in the NP rate because in regions with different ULUs, different activities are conducted that lead to different noise levels. Therefore, the ULU parameter can directly be used in predicting the NP and it can help the urban managers to have more accurate planning for controlling the NP. Some studies have been conducted to survey the level of noise pollution in some urban land use so far, for example, Doygun and Gurun (Doygun and Kusat Gurun, 2008), Hunashal and Patil (Hunashal and Patil, 2012), Zannin et al. (Zannin et al., 2002), Morillas et al. (Barrigón Morillas et al., 2002) have investigated the NP in some ULUs, such as residential, commercial, industrial, recreational, educational, and road areas. However, the role of this type of ULU and other ULUs, such as green space, parking, idle lands, and land use for public service in NP has not been fully evaluated, and it is necessary to perform detailed studies to predict more accurate the areas which are exposed to NP.

Tehran is one of the highly populated cities in the world, it burdened with various environmental pressures such as NP. So far, few studies have been conducted to investigate the NP in Tehran. One of the aims of the present research is to prepare the acoustic map of the most populous and busiest districts of Tehran in different hours of the day using GIS and make a proper framework to adopt sound reduction policies and tools. Another aim is the evaluation of the ULU effect on the NP rate.

\section{Materials and methods}

\subsection{Study area}

Tehran has an extend of $574 \mathrm{~km}^{2}$ inhabited by 14 million people according to the last census that conducted in 2017 and it is the 25th most populous city in the world. The height of the city at its highest point is about 2000 meters above the sea level in the north and the lowest point is 1050 meters above the sea level in the south. The climate in northern parts of this city is cold and dry and the southern regions are warm and dry. In the last 40 years, Tehran has had huge economic and industrial growth.

Tehran is divided into 22 districts (Figure 1). In this research, district 6 was selected to evaluate because based on the noise monitoring stations, it had the maximum NP among the different districts in Tehran city. The population of the study area was determined to be 384,251 . District 6 has a dense population and traffic during the day and the density of buildings, residential, and commercial apartments is considerable. In this area, trucks do not allow traveling during the day and only city vehicles and buses can travel. BRT (Bus Rapid Transit) lines that use vehicles with a diesel engine (with a high level of sound pressure) are present in most of the area. Motorcycle traffic is also higher than in other areas.

\subsection{Noise evaluation and measurement}

170 temporary sampling stations were randomly selected in the study area in a way that took into consideration all types of land use, i.e., roads, industrial, commercial, mixed commercial and residential, residential, idle lands, parking, and public service land uses. Figure 1 shows the distribution of the sampling stations spread through the study area. All measurements were carried out during the winter in 2018 (temperature -3 to 18 degrees celsius). The latitude and longitude of each station were determined by the GPS (MAGELLAN, model -315).

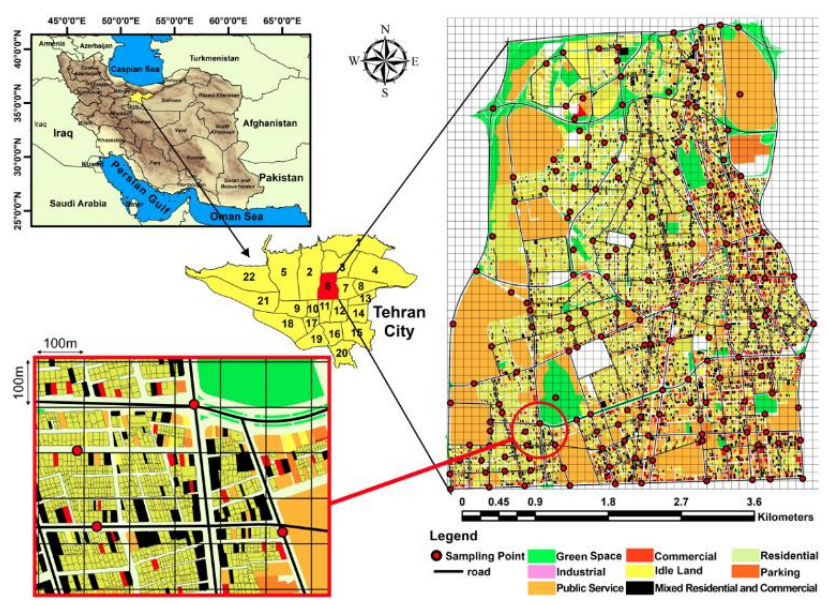

Figure 1. Noise measurement stations and urban land use in district 6 of Tehran

In accordance with ISO1996-2, at the sampling stations, Aweighted continuous equivalent sound level (Leq) was measured using Cacella Cel sound level meter (model-CEL 268 Environmental Noise Meter, England). The sound level meter was kept at a height of 1.5 meters above ground level and 3 meters away from any reflector surface. For each station, measurements were performed continuously for 1 day, at intervals (morning-noon-afternoon) during weekdays (with 12 hours of follow-up per day). The program selected during the day is as follows: morning from 7 a.m. to 11 a.m., noon from 11 a.m. to 3 p.m., afternoon from 3 p.m. to 7 p.m. For each time interval, the sound level was recorded every 5 minutes (for example, 12 readings per hour). Data were evaluated using the equivalent continuous sound pressure level (Leq) (Tsai et al., 2009; Xie et al., 2011).

\subsection{Acoustic mapping and the relationship between land use and noise pollution}

To prepare the acoustic map, the ULU map related to district 6 of Tehran was prepared (Figure 1). In addition, the location of the sampling stations was imported in ArcGIS software as a layer and the $L_{e q}$ values were determined for each station. Then, an acoustic map for the morning, noon, and the afternoon was separately provided using the kriging interpolation method. Also, the areas with the highest and lowest NP rate (with 90, 95, and 99\% 
confidence intervals) were determined on the map by hot spot analysis. To investigate the relationship between ULU type and noise level, roads, industrial, commercial, mixed commercial and residential, residential, idle lands, parking, and public service land uses were extracted separately from land use map and saved in separate layers. Furthermore, satellite images were employed to prepare the green land map of the area. For this purpose, the Normalized Differential Vegetation Index (NDVI) images were utilized. NDVI images prepare a map of biomass from the study area. The chlorophyll absorption in red band and relatively high reflectance of vegetation in the NearInfrared band (NIR) were used in order to calculate NDVI. To classify the NDVI images, the maximum likelihood classification method was used and then the accuracy of the prepared map was approved by comparing it with aerial images. Afterward, the prepared green land map was saved as a separate ULU type layer. The density of each mentioned ULU types were prepared using the kerneldensity method. Then, the study area was divided into 2240 cells $(100 \times 100 m$ cells) (Figure 1$)$ and the mean density of each ULU types were calculated for each cell. In terms of vegetation density, the vegetation area was calculated in each cell $\left(10000 \mathrm{~m}^{2}\right)$. In the case of roads, the total length of the paths in each of the designated cells was calculated. The densities obtained for each ULU type were compared with the prepared NP map of the studied area, thus, the effect of ULU on the level of NP was investigated. Kruskal-Wallis test was used to determine the significance of Leq differences in different periods and the Signed ranksum test was utilized for comparison of Leq values with the standards. Besides, the spatial analysis was performed using ArcGIS v10.1 software and to statistical analysis of collected data, SPSS v15 and Excel 2010 (Microsoft Office Package) were used.

\section{Results and discussion}

\subsection{Temporal and spatial assessment}

Studies about the Tehran environmental NP are rare. Collection and analysis of NP data are one of the main elements of the assessment and management of urban environmental noise (Jamrah et al., 2006). Therefore, in the present research, the noise level in 170 stations was measured in morning, noon, and afternoon to evaluate the NP in one of the busiest areas in Tehran. The results are presented in Table 1. According to Table 1, in the morning, the mean $L_{e q}$ was $76.29 \mathrm{~dB}[\mathrm{~A}]$. Moreover, in noon and afternoon, the mean Leq respectively were 75.75 and 76.46 $\mathrm{dB}[\mathrm{A}]$. The NP higher than $55 \mathrm{~dB}[\mathrm{~A}]$ can cause aggressive behavior and sleeping disorder (Berglund et al., 1999). Also, long-time exposure to $65 \mathrm{~dB}[\mathrm{~A}]$ might lead to hypertension; and stress levels, heart rates, and potential hearing loss would be increased at $75 \mathrm{~dB}[\mathrm{~A}]$ (Doygun and Kusat Gurun, 2008). Noise exposure consequences might be worse for particular subgroups such as children, elderlies, and lower socioeconomic groups (Lagonigro et al., 2018). The Iranian Department of Environment considers $55,60,70$, and $75 \mathrm{~dB}[\mathrm{~A}]$ as the standard NP level for residential, commercial-residential, commercial, residential-industrial, and industrial area, respectively (Monazzam et al., 2015). Therefore, the results demonstrate that the study area is severely noise polluted. Other studies that were conducted in Yazd province in Iran and district 14 of Tehran reported that the mean Leq was 74.41 (70.9-80.7) and 72 (62.3-84.2) $\mathrm{dB}[\mathrm{A}]$, respectively. Morillas et al. (Barrigón Morillas et al., 2002) performed a study in a small and non-industrial city in Spain and reported that in the $90 \%$ of noise measurements, Leq has recorded higher than $65 \mathrm{~dB}[\mathrm{~A}]$. Deniz Çolakkadıog ${ }^{\circ}$ and Muzaffer Yücel conducted a study in Adana city center in Turkey and showed that in 63 percent of evaluated lands, Leq value is higher than $68 \mathrm{~dB}[\mathrm{~A}]$ during the day (Çolakkadıoğlu and Yücel, 2017). Fiedler and Zannin found that in the 73 percent of the noise measurement stations in the Curitiba in southern Brazil, the noise level was higher than $65 \mathrm{~dB}[\mathrm{~A}]$ (Fiedler and Zannin, 2015). In the present research, the studied area is located in the inner city and the existence of many commercial, industrial and official centers, as well as a high density roads and highways, explain this high NP level.

The results of the Kruskal-Wallis test indicated that no significant difference was observed between Leq values in the morning, noon, and afternoon ( $P$-value $>0.05$ ), but according to Table 1 , the mean of $L_{e q}$ in noon was lower than that of morning and afternoon. Since in the studied area, there are many educational, commercial, and public service centers, in the morning, many people travel to these centers and in the afternoon, they come back home. Also, in the afternoon, people come to shopping centers and recreation places, which lead to increasing Leq values in the morning and afternoon. Several studies have shown a similar pattern. For instance, Hakan Doygun and Derya Kuşat Gurun found that the minimum and maximum NP occurred during the mid-day and evening hours in Turkey (Doygun and Kusat Gurun, 2008). In another study, Hunashal and Patil performed a study in Kolhapur city and reported the maximum $L_{e q}$ in industrial and commercial regions in the afternoon (4-5 p.m.) (Hunashal and Patil, 2012). Moreover, in Karachi city in Pakistan, such as our findings, the noise level in the morning and afternoon was higher than that in the noon and mean Leq measured in the morning, noon, and afternoon respectively were reported 79, 73, and $80 \mathrm{~dB}[\mathrm{~A}]$ (Mehdi et al., 2011).

Acoustic mapping is an important task to develop methods for controlling NP (Jamrah et al., 2006). Therefore, we aimed at preparing an acoustic map from the studied area. For this purpose, after determining Leq of each station, an acoustic map of each interval was plotted using a kriging interpolation method (Figure 2). According to Figure 2, in all the studied intervals (morning, noon, and afternoon) the Leq values in the eastern regions of the surveyed area were the highest so that in all studied time intervals, Leq values were determined between 81 to $86 \mathrm{~dB}[\mathrm{~A}]$. The acoustic map of the studied area demonstrated that the NP level in the center and the west side of the area was medium while it was minimum in the southwest of the area. Finally, the Leq value was lower than $72 \mathrm{~dB}[\mathrm{~A}]$ for all studied time intervals. The prepared map showed that in the morning, 
NP expansion rate in the east of the studied area was higher than noon and afternoon; in contrast, in the afternoon, the area with a Leq higher than $81 \mathrm{~dB}[\mathrm{~A}]$ was denser and smaller, while the areas with NP of 69-72 $d B[A]$ and $78-79 d B[A]$ were more expanded (Figure 2).

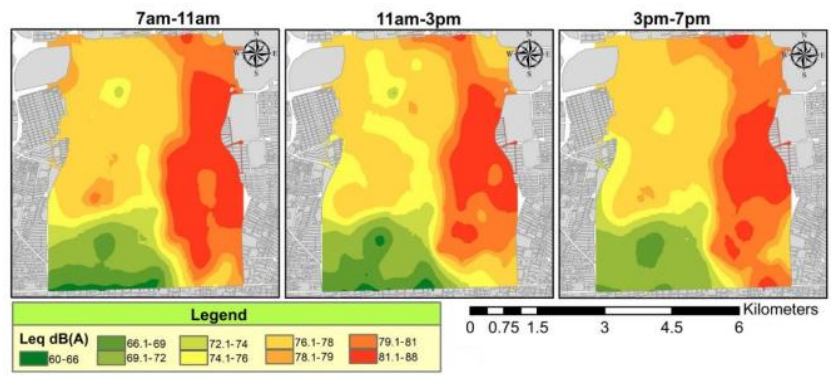

Figure 2. The acoustic map of the studied area in the morning, noon, and afternoon

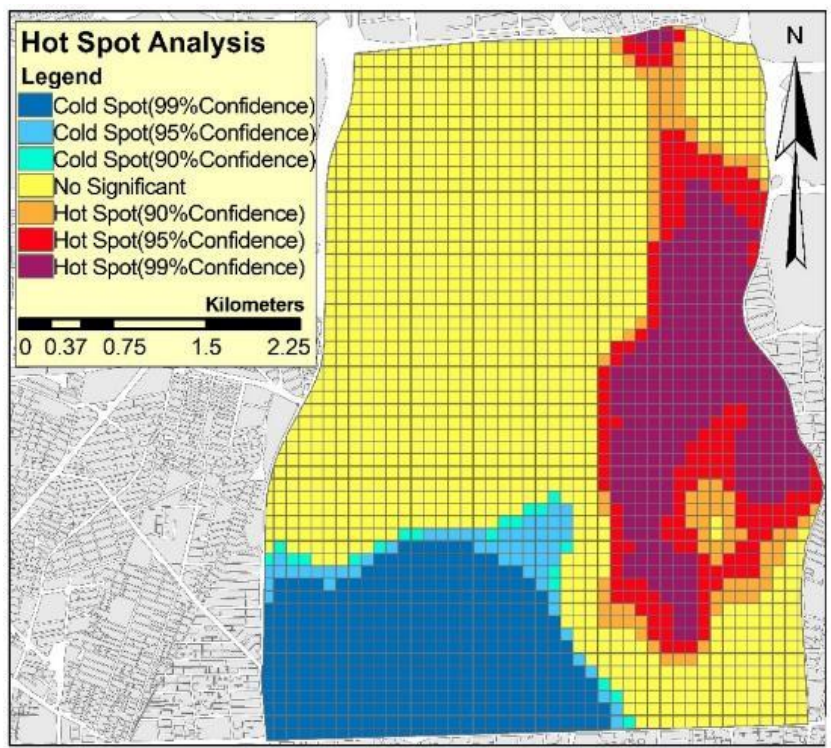

Figure 3. Hot spot analysis of noise pollution in the studied area

Furthermore, in all three investigated intervals, the areas with Leq of 74-79 dB[A] (areas with yellow and light orange colors) almost cover all the north, center and west of the studied area. Only in the morning, small parts in the center and northwest have $L_{e q}$ in the range of 78-81 dB[A]. In order to confirm the most polluted parts of the studied area, Hot spot analysis was performed on all data collected in the morning, noon, and afternoon overlay, and the results are depicted in Figure 3. According to Figure 3, the most polluted parts are located in the east of the studied area; hence, Tehran municipality managers should put the polluted points on the priority of NP control plans. Besides, the southern and southeastern regions of the studied area had the lowest NP compared to the rest of the studied points, although the values obtained for this area also exceeded the standards (Figure 2).

The mean, minimum, and maximum $L_{e q}$ values were determined in regions with different ULUs using the prepared acoustic map; and the obtained results are presented in Table 2. The results showed that the areas with cultural and parking use had the lowest (73.48 \pm $4.7 \mathrm{~dB}[\mathrm{~A}])$ and the highest (79.02 $\pm 4.3 \mathrm{~dB}[\mathrm{~A}]) \mathrm{NP}$, respectively. There are usually dense green spaces around cultural areas such as museums, theaters, mosques, and libraries, hence a lower $L_{e q}$ is expected in such places. On the other hand, areas similar to the parking check point have the highest $L_{e q}$ among the other ULUs. It can be explained that this place usually is located in the busiest part of the cities and in most of the time the traffic of cars is heavy in such areas. According to Table 2, none of the ULUs could meet the standards of the Iranian Department of Environment. Many other studies that have been carried out in the cities of other countries have determined $L_{e q}$ values for different ULUs, for example, in Kahramanmaraş city, the Leq values respectively were 62 and $68 \mathrm{~dB}[\mathrm{~A}]$ in the residential and industrial regions (Doygun and Kusat Gurun, 2008). In another study in India, in the commercial and industrial area, Leq was 72.25 and $65.3 \mathrm{~dB}[\mathrm{~A}]$, respectively (Hunashal and Patil, 2012). Also, Kisku et al. performed a study in Lucknow (India) and reported that Leq average in residential and commercial areas was 64.06 and $74.48 \mathrm{~dB}[\mathrm{~A}]$, respectively (Kisku et al., 2006). In all of the studies, Leq was significantly lower than the values obtained in this study. Among 2240 studied cells (Figure 1) 90 percent of them had to mean Leq over $71 \mathrm{~dB}$, which confirmed a high NP in the studied area. As seen in Table 2, the Leq value of different ULUs are as follows: Cultural < Health Centers < Educational < Idle Land < Residential < Public Service < Mixed Residential and Commercial < administrative $<$ Industrial $<$ Commercial $<$ Parking.

\subsection{The relationship between land use and noise pollution}

ULU composition can deeply affect the environmental noise, so the combination of ULU in a city can be used to predict and manage the NP. As mentioned, in order to evaluate the association between the ULU and Leq, authors selected the most important ULUs that might have a relationship with Leq; they included commercial, industrial, roads, idle lands, residential, mixed commercial and residential, green land, public service, and parking spots. We determined the density (in $\mathrm{km}^{2}$ ) of each ULU in separate layers (except roads and green land, in which length and area of each cell were calculated) (Figure 4). In addition, hot spot analysis was used to determine statistically the areas with the highest and lowest density and the results are illustrated in Figure 5. Moreover, in order to further investigate about the effect of ULU on the Leq level, the Leq values in the hot spot areas and the cold spot areas were separately compared in each ULUs (Figure 6). To determine the significance in the noise level difference between two areas with hot and cold spots, the Mann-Whitney test was employed and Spearman's coefficient of rank correlation (rho) was used to evaluate the relationship between the ULU and noise level. 
Table 1. Leq values measured in the morning, noon, and afternoon

\begin{tabular}{ccccccccc}
\hline \multirow{2}{*}{ Period } & \multicolumn{9}{c}{$\mathrm{L}_{\mathrm{eq}} \mathrm{dB}[\mathrm{A}]$} & \multicolumn{3}{c}{ Percentiles } \\
\cline { 2 - 10 } & mean & $\mathbf{9 5 \%} \mathrm{Cl}$ for mean & S.D & median & lowest-highest & $\mathbf{1 0}$ & $\mathbf{7 5}$ & $\mathbf{9 0}$ \\
\hline Morning & 76.29 & 75.44 to 77.14 & 5.61 & 77 & $62.2-87.2$ & 67.85 & 80 & 82.65 \\
\hline Noon & 75.75 & 74.95 to 76.56 & 5.31 & 76.75 & $60.5-86$ & 68.3 & 79.2 & 82 \\
\hline Afternon & 76.46 & 75.72 to 77.2 & 4.88 & 77 & $62.5-86.5$ & 69.5 & 80 & 83 \\
\hline Overall & 76.17 & $75.71-76.63$ & 5.28 & 77 & $60.5-87.2$ & 68.8 & 80 & 82.3 \\
\hline
\end{tabular}

Table 2. The mean value, minimum, and maximum $L_{e q}$ in different land uses

\begin{tabular}{cccccc}
\hline Land Use Type & Count & Area $\left(\mathbf{m}^{\mathbf{2}}\right)$ & Percentage in total area (\%) & Mean (dB[A]) & Min-Max (dB $[\mathrm{A}])$ \\
\hline Cultural & 53 & 114131.25 & 0.76 & $73.48 \pm 4.7$ & $64.41-83.04$ \\
\hline Health Centers & 199 & 482399.04 & 3.24 & $74.01 \pm 4.6$ & $67.24-83.27$ \\
\hline Educational & 532 & 2293055.77 & 15.2 & $75.50 \pm 3.1$ & $66.12-83.47$ \\
\hline Idle Land & 2109 & 855005.41 & 5.75 & $76.99 \pm 3$ & $66.42-83.52$ \\
\hline Residential & 49566 & 6130102.42 & 40.1 & $77.01 \pm 3.7$ & $66.47-83.42$ \\
\hline Public Service & 838 & 429961.49 & 2.91 & $77.34 \pm 4.46$ & $66.31-83.53$ \\
\hline $\begin{array}{c}\text { Mixed Residential \& } \\
\text { Commercial }\end{array}$ & 10209 & 1472158.11 & 9.9 & $77.35 \pm 4.4$ & $66.22-83.49$ \\
\hline administrative & 1559 & 1559277.92 & 10.2 & $77.76 \pm 3.8$ & $66.26-84.63$ \\
\hline Industrial & 383 & 55394.22 & 0.37 & $78.03 \pm 4.5$ & $66.52-83.17$ \\
\hline Commercial & 4281 & 693686.59 & 4.66 & $78.26 \pm 4.3$ & $66.28-83.63$ \\
\hline Parking & 499 & 302795.56 & 2.03 & $79.02 \pm 4.3$ & $66.35-83.27$ \\
\hline
\end{tabular}

As seen in Figure 4, in the east of the studied area, the density of the number of commercial land use is more than other parts, so that in some parts of eastern areas, the density reaches 756 to 1087 per $\mathrm{Km}^{2}$. Also, Figure 5 confirms that the eastern region with $99 \%$ confidence interval has the most areas with a high density of commercial use and according to Figure 3, the eastern region is located in a high NP zone that is probably due to the high number of commuters as well as the high traffic congestion in commercial areas. Figure 6 illustrates that median of the noise level in the areas with a high density of commercial use (Hot spot areas) is $80.55 \mathrm{~dB}[\mathrm{~A}]$, which is significantly higher compared to Cold spot area $(76.65$ $\mathrm{dB}[\mathrm{A}]$ ); Mann-Whitney test determined that this difference is significant $(U=88486, P<0.0001)$. Besides, it is revealed that an increase in the density of commercial land use leads to increasing NP $(r=0.38, P<0.0001)$.

Also, the density pattern of the industrial areas completely matched with the distribution pattern of NP, so that in the east part of the study area, the areas with high industrial density (over 29-40 per $\mathrm{Km}^{2}$ ) was significantly higher and even some parts of the eastern area had a density over 37 number per $\mathrm{km}^{2}$. Moreover, Hot spot analysis showed, with a $99 \%$ confidence interval, the east part had the highest industrial density (Figure 5). Also, according to Figure 6, the median of the noise level in the industrial dense area (81.08 $\mathrm{dB}[\mathrm{A}]$ ) was significantly higher than the low-density region (76.51 dB[A]) and the difference was significant ( $U=50044$, $\mathrm{P}<0.0001)$. In the industrial zones, the traffic of noisy trucks and big cars for transporting is obviously higher in comparison to other areas, and also the noisy activities of industrial machines could enhance NP in such areas; hence, it is expected that increasing of the industrial land use density is correlated with high NP. In our research, the correlation test confirmed that an increase in density of the industrial land use resulted in an increase in NP ( $r=0.42$, $\mathrm{P}<0.0001)$.

Roads are one of the most important factors in the amplification of NP in communities. Some studies have shown the relationship between the increase in road density and the traffic of cars with an increase in Leq (Barrigón Morillas et al., 2002; Çolakkadıoğlu and Yücel, 2017; Jamrah et al., 2006). In Tehran, 4 million cars are traveled daily, while it is estimated that the capacity of Tehran's street is only 750000 cars. This issue has caused heavy traffic congestion in the metropolis, resulting in significant NP in this city. In the present survey, due to some limitations, there was no possibility of measuring the number of vehicles traveling on the roads of the studied area; therefore, only the effect of road density on the NP was addressed. In highways, the ever-increasing number of cars and their high speed leads to making more problem for the environment compared to other road types (Alesheikh and Omidvari, 2010), so the weight of $4,3,2$, and 1 respectively were considered for highways, major roads, arterial roads, and collector roads and then the length of the roads was determined in each cell (Figure 4). As seen in Figure 4, the density of roads is somewhat higher in the east of the region, and in contrast, in the west, the lowdensity points with a density of $0-5 \mathrm{~m} / 1000 \mathrm{~m}^{2}$ are considerably more than the eastern regions of the study area, however, low-density points are observed in the eastern parts. Hot spot analysis showed that although in the eastern region NP is high, there is no hot spot for roads. But in the western region where the NP is low, there is clearly a Coldspot with 90 and $95 \%$ confidence interval, indicating that lower road density is likely to result in a reduction of noise levels. Apart from the effect of shape, geometry, and height of buildings in a street, Morillas et al. showed that NP is generally lower in areas with small streets compared to two-way roads because of lower 
traffic in such streets (Barrigón et al., 2002). In the present study, the western region has more arterial and collector roads compared to other regions, which leads to lower NP. Figure 6 shows that areas with a high density of road have higher Leq (77.46 dB[A]) compared to areas with lower density (76.59 $\mathrm{dB}[\mathrm{A}])$ and the difference is significant $(\mathrm{U}=23936, \mathrm{P}<0.0001)$. Also, the results revealed that an increase in road density resulted in an increase in NP $(r=0.73, P<0.0001)$.

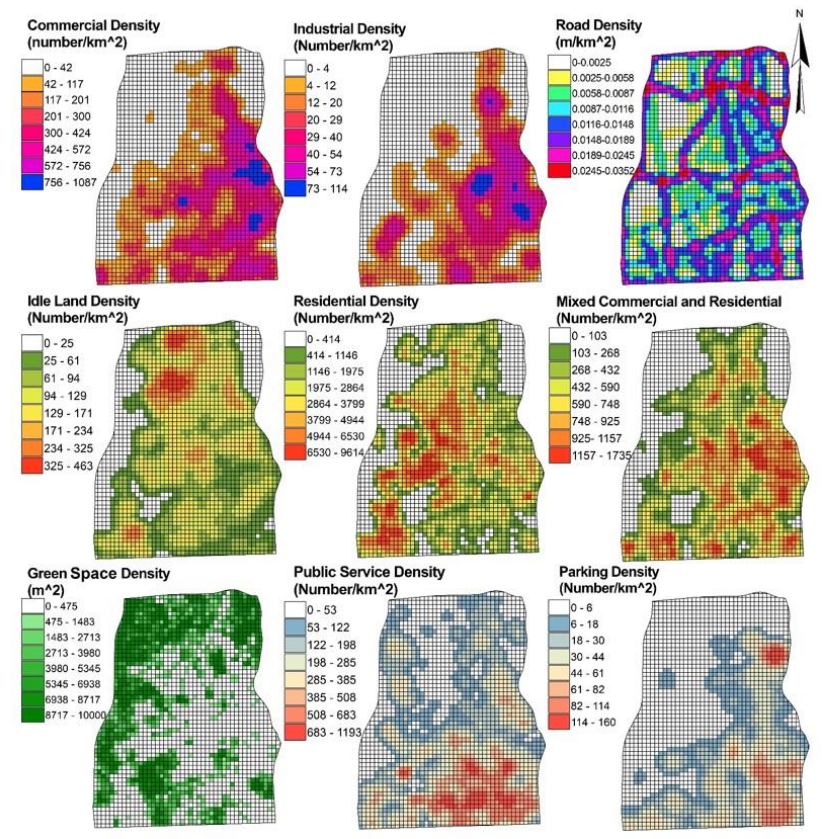

Figure 4. The density map of urban land use for the studied area

In Idle lands, high levels of sound are expected due to construction and demolition as well as the high activities of construction vehicles. On the other hand, in these areas, common urban traffic and buildings density are low, which can also reduce the NP in these areas; Han et al. showed a direct relationship between buildings density and NP (Han et al., 2018). Since no study has been done on the relationship between the density of this type of ULU and $\mathrm{NP}$, in the present study, the effect of this density on NP was investigated. The results showed that the areas in the north and the small area in the southwest of the studied area had a density of over 234 number per km² (Figure 4), and in contrast, the areas in the northeastern and western regions had a density less than 25 per $\mathrm{km}^{2}$. These areas are well featured in Hot spot analysis (Figure 5). Considering the Figure 5, The location of areas with a Coldspot and Hot spot does not match with the pattern of NP in Figure 2. As seen in Figure 6, a small difference between the median of noise levels in Coldspot (76.59 dB[A]) and Hot spot (76.82 $\mathrm{dB}[\mathrm{A}])$ areas is observed and this difference was not statistically significant $(\mathrm{U}=136320.5, \mathrm{P}=0.093)$.

According to Figure 4, the maximum residential density was found in the central and southwest parts of the study area, although some Hot spots were observed in the eastern part (Figure 5). Most residential uses are located in areas with lower NP, which leads to more populations being exposed to lower levels of pollution. The existence of residential areas can also reduce the NP, as the traffic in these areas is generally lower than in commercial and industrial areas. However, the results of the study showed that there was no significant difference between the areas with high density and low density of residential use $(\mathrm{U}=189310.5, \mathrm{P}$ $=0.144)$, and there was no relationship between increasing the density of this ULU and increasing $L_{e q}(r=-0.04, P=0.07)$. Nevertheless, when the residential area is blended with commercial land use, the potential for noise generation will increase because of the growing number of activities and movements in these areas. In a study performed in Turkey, the mixed residential and commercial areas showed the highest NP in comparison with other ULUs (Doygun and Kusat Gurun, 2008). As shown in Figure 4, the mixed commercial and residential densities in the eastern region reach over 1157 number per $\mathrm{km}^{2}$, although this density is also more dispersed in areas located in the south, southeast, and southwest. Figure 5 also shows that the focus of such coverage with a $99 \%$ confidence interval is in the eastern region, which has the highest degree of NP. On the other hand, areas with the lowest density of this type of ULU (with 99\% confidence interval) are found in the western part, a small part of the northeast, and southwest; these areas are less polluted. The results showed that there was a significant difference between the median of $L_{e q}$ in the high-density (79.05 dB[A]) and low-density (76.67 $\mathrm{dB}[\mathrm{A}]$ ) mixed commercial and residential regions. Besides, the statistical analysis revealed that this difference was significant $(U=176307.5, P<0.0001)$. In addition, the correlation between $\mathrm{Leq}_{\mathrm{a}}$ and mixed commercial and residential density was significant $(r=0.26, P<0.0001)$.

Green land is another ULU that can effectively affect the NP of urban areas. In cities, it has been proven that places where porosity and green space coverage are more developed, the rate of NP is also lower (Han et al., 2018; Margaritis and Kang, 2017). In addition, soils with higher vegetation are also generally more permeable, and soils with high permeability have more acoustic absorption potential (Han et al., 2018). The present study showed that a large part of the north, west, and southwest regions have vegetation over $8717 \mathrm{~m}^{2} / 10000 \mathrm{~m}^{2}$. Of course, small parts in the south and southeast also had such a density. However, according to Figure 5, the center and east regions with the $95 \%$ confidence interval have the lowest vegetation. Considering Figs. 2 and 3, it can be concluded that in places with less vegetation, the level of NP is significantly increased. It should be noted that noise reduction is usually done in the green area and the park itself compares to streets around. For example, Margaritis et al. determined the noise in parks in a lower level than the around streets, they concluded that this issue occurred due to the proximity of noise source to the streets (Margaritis et al., 2018). However, it is obvious that green space is a good absorbent for sound due to its surface and porosity characteristics and it is effective in reducing the sound of the environment (Margaritis and Kang, 2017). Also, in areas with dense vegetation, car traffic is usually less, and this can be a factor in reducing NP in such areas. According to Figure 6, areas with higher green space density have a lower median (72.69 dB[A]) of Leq compared to a region with lower density (74.46 $\mathrm{dB}[\mathrm{A}])$, which the 
difference was significant $(U=170275, \quad P<0.0001)$. Correlation analysis indicated that there is a reverse significant relationship between the increasing green land density and Leq level $(r=-0.2, P<0.0001)$.

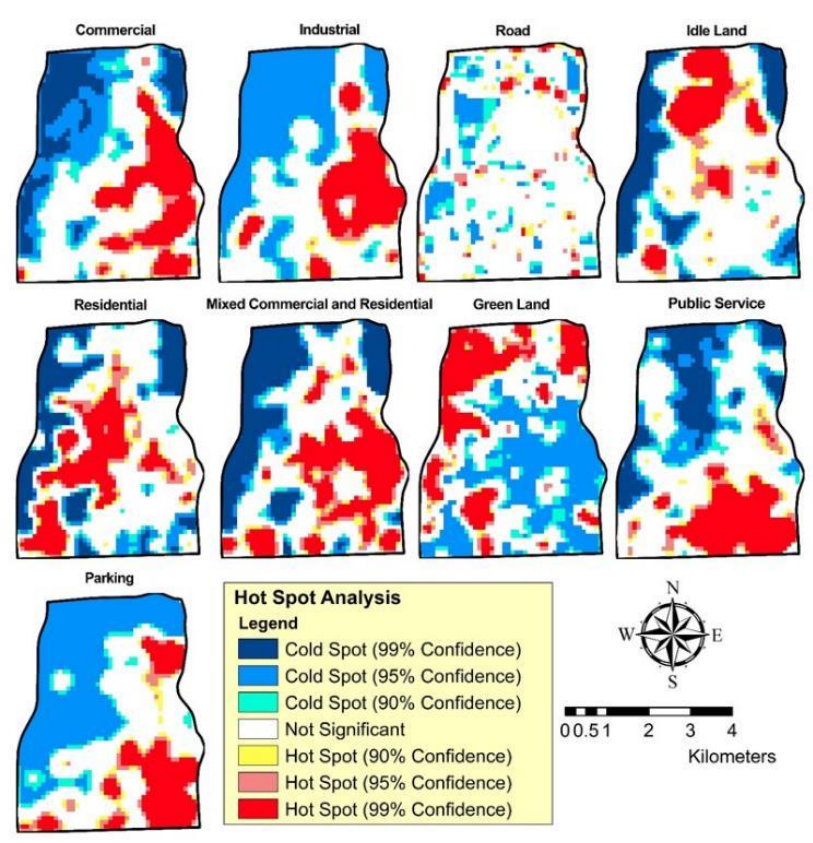

Figure 5. The Hot spot analysis for different urban land uses

As shown in Figs. 4 and 5 , in the southern and eastern parts of the studied area, the density of public service (such as ministries, government departments, etc.) is high that the density pattern of the land use did not match with the prepared acoustic map of the studied area. Public service centers are usually expected to have higher levels of NP due to high traffic. As seen in Figure 6, the median of Leq in areas with the high and low density of public service were respectively $77.84 \mathrm{~dB}[\mathrm{~A}]$, and $76.91 \mathrm{~dB}[\mathrm{~A}]$, which showed that the pollution rate in Hot spot is higher but there is no significant difference $(U=201907, P=0.75)$ and no relationship was observed between the density and Leq $(r=0.01, P=0.56)$.

Car traffic in parking cause an increase in NP in these places and streets around, because traffic is one of the main sources of noise in the urban environment (Guedes et al., 2011; Jamrah et al., 2006). The results of the current study indicated that the high density of parking in the eastern and southern parts is more than in other parts. As seen in Figure 4 , these areas are the main location of commercial and industrial uses. Figure 5 shows that in the eastern and southeast of the study area with a $99 \%$ confidence interval, the number of parking is higher than in other parts. It is of note that the small parts in the southwest were also determined as a Hot spot. As seen in Figure 6, in locations with a high density of parking, the median is significantly higher than the areas with low density $(U=143299$, $\mathrm{P}<0.0001)$. Moreover, the result showed that there is a significant and direct relationship between parking density and $L_{\text {eq }}(r=0.26, P<0.0001)$.
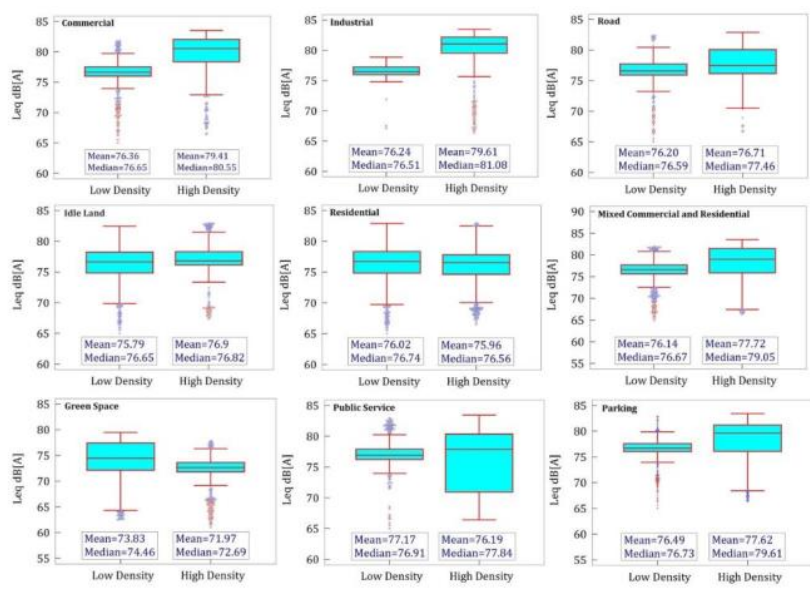

Figure 6. The comparison of Leq in Hot and Coldspot areas

\section{Conclusion}

In the present study, the acoustic map of district 6 in Tehran was prepared by measuring the noise level in different stations. The result showed that in the study area, the mean noise level was $76.17 \mathrm{~dB}[\mathrm{~A}]$, which is higher than the national and international standards. Moreover, in the afternoon (3-7 p.m.), the noise level (76.46 dB[A]) was higher than that in the morning and noon. The results showed that the east of the study area has higher NP than other areas, which indicates that NP control in this area has a major priority. In addition, the southwest region also has the lowest NP. Moreover, the relationship of ULUs including commercial, industrial, roads, idle lands, residential, mixed commercial and residential, green land, public service, and parking, was investigated with NP. The results showed that in areas with a high density of road, parking, commercial, industrial and mixed commercial and residential land uses, Leq level is significantly high and there is a significant relationship between the increased density of these ULUs and Leq. Moreover, a reverse relationship is observed between the green land area density and Leq and in areas with a higher density of green land, the lower NP was recorded. Besides, to control the NP, the following action is recommended: developing the green lands in areas with high NP (the east part), banning the traveling of noise making cars to the study area, especially in morning and afternoon, developing the standard public transportation system to reduce the traffic, provision of rigorous rules to control traffic and prevent the accumulation of cars on the streets, forcing automobile factories to use low-noise and standard engines, restricting the construction of large commercial and industrial centers in areas where NP is high.

\section{References}

Abbaspour M., Karimi E., Nassiri P., Monazzam M.R. and Taghavi L. (2015), Hierarchal assessment of noise pollution in urban areas-A case study, Transportation Research Part D: Transport and Environment, 34, 95-103.

Alam W. (2011), GIS based assessment of noise pollution in Guwahati City of Assam, India, International Journal of Environmental Sciences, 2, 731-740. 
Alesheikh A.A. and Omidvari M. (2010), Application of GIS in urban traffic noise pollution, International Journal of Occupational Hygiene, 2, 79-84.

Aparicio-Ramon D.V., Morales M.S.-V., Garcia A.G., Llopis A.G., Ruano L., Sanchez A.M. and Ferrer E.C. (1993), Subjective annoyance caused by environmental noise, Journal of Environmental Pathology, Toxicology and Oncology: Official Organ of the International Society for Environmental Toxicology and Cancer, 12, 237-243.

Barrigón Morillas J.M., Gómez Escobar V., Méndez Sierra J.A., Vílchez Gómez R. and Trujillo Carmona J. (2002), An environmental noise study in the city of Cáceres, Spain, Applied Acoustics, 63, 1061-1070.

Berglund B., Lindvall T., Schwela D.H. (1999), Guidelines for community noise, World Health Organazation, Geneva, URL: http://whqlibdoc.who.int/hq/1999/a68672.pdf (last date accessed: May 20, 2020).

Çolakkadıoğlu D. and Yücel M. (2017), Modeling of Tarsus-AdanaGaziantep highway-induced noise pollution within the scope of Adana city and estimated the affected population, Applied Acoustics, 115, 158-165.

Doygun H. and Kusat Gurun D. (2008), Analysing and mapping spatial and temporal dynamics of urban traffic noise pollution: a case study in Kahramanmaras, Turkey. Environmental Monitoring and Assessment 142, 65-72.

Environment I.D.O. (1999), The equivalent sound pressure level in ambient air of Iran, 1999 [cited 2013 Oct 12]. Available from: http://www.DOE.ir. Persian. In. Iran: Department of Environment.

Fiedler P.E.K. and Zannin P.H.T. (2015), Evaluation of noise pollution in urban traffic hubs-Noise maps and measurements. Environmental Impact Assessment Review, $51,1-9$.

Guedes I.C., Bertoli S.R. and Zannin P.H. (2011), Influence of urban shapes on environmental noise: a case study in Aracaju-Brazil, Science of the Total Environment, 412-413, 66-76.

Hamed M. and Effat W. (2007), A GIS-based approach for the screening assessment of noise and vibration impacts from transit projects, Journal of Environmental Management, 84, 305-313.

Han X., Huang X., Liang H., Ma S. and Gong J. (2018), Analysis of the relationships between environmental noise and urban morphology. Environmental Pollution, 233, 755-763.

Hunashal R.B. and Patil Y.B. (2012), Assessment of noise pollution indices in the city of Kolhapur, India, Procedia-Social and Behavioral Sciences, 37, 448-457.

Jamrah A., Al-Omari A. and Sharabi R. (2006), Evaluation of traffic noise pollution in Amman, Jordan, Environmental Monitoring and Assessment, 120, 499-525.

Kisku G., Sharma K., Kidwai M., Barman S., Khan A., Singh R., Mishra D. and Bhargava S. (2006), Profile of noise pollution in Lucknow city and its impact on environment, Journal of Environmental Biology, 37, 409-412.

Lagonigro R., Martori J.C. and Apparicio P. (2018), Environmental noise inequity in the city of Barcelona, Transportation Research Part D: Transport and Environment, 63, 309-319.

Langdon F.J. (1976), Noise nuisance caused by road traffic in residential areas: Part I, Journal of Sound and Vibration, 47, 243-263.
Lercher P. (1996), Environmental noise and health: An integrated research perspective, Environment International, 22, 117129.

Margaritis E. and Kang J. (2017), Relationship between green space-related morphology and noise pollution, Ecological Indicators, 72, 921-933.

Margaritis E., Kang J., Filipan K. and Botteldooren D. (2018), The influence of vegetation and surrounding traffic noise parameters on the sound environment of urban parks, Applied Geography, 94, 199-212.

Mehdi M.R., Kim M., Seong J.C. and Arsalan M.H. (2011), Spatiotemporal patterns of road traffic noise pollution in Karachi, Pakistan, Environment International, 37, 97-104.

Monazzam M.R., Karimi E., Abbaspour M., Nassiri P., Taghavi L. (2015), Spatial traffic noise pollution assessment - A case study, International Journal of Occupational Medicine and Environmental Health, 28, 625-634.

Ouis D. (2001), Annoyance from road traffic noise: a review, Journal of Environmental Psychology, 21, 101-120.

Ryu H., Park I.K., Chun B.S. and Chang S.I. (2017), Spatial statistical analysis of the effects of urban form indicators on road-traffic noise exposure of a city in South Korea, Applied Acoustics, 115, 93-100.

Steele C. (2001), A critical review of some traffic noise prediction models, Applied Acoustics, 62, 271-287.

Tsai K.-T., Lin M.-D. and Chen Y.-H. (2009), Noise mapping in urban environments: A Taiwan study, Applied Acoustics, 70, 964972.

Williams I. and McCrae I. (1995), Road traffic nuisance in residential and commercial areas, Science of The Total Environment, 169, 75-82.

Xie D., Liu Y. and Chen J. (2011), Mapping Urban Environmental Noise: A Land Use Regression Method, Environmental Science \& Technology, 45, 7358-7364.

Zannin P.H.T., Diniz F.B. and Barbosa W.A. (2002), Environmental noise pollution in the city of Curitiba, Brazil, Applied Acoustics, 63, 351-358. 